\title{
BMJ Open Productivity loss due to overweight and obesity: a systematic review of indirect costs
}

\author{
Andrea Goettler, ${ }^{1}$ Anna Grosse, ${ }^{1}$ Diana Sonntag ${ }^{1,2}$
}

To cite: Goettler A, Grosse A, Sonntag D. Productivity loss due to overweight and obesity: a systematic review of indirect costs. BMJ Open 2017;7:e014632. doi:10.1136/ bmjopen-2016-014632

- Prepublication history and additional material for this paper are available online. To view these files, please visit the journal online (http://dx.doi. org/10.1136/bmjopen-2016014632 ) .

Received 12 0ctober 2016 Revised 28 August 2017 Accepted 31 August 2017
CrossMark

${ }^{1}$ Mannheim Institute of Public Health, Social and Preventive Medicine, University Medicine Mannheim, Heidelberg University, Mannheim, Germany ${ }^{2}$ Department of Health Sciences, University of York, York, UK

Correspondence to Dr Diana Sonntag; mail@diana-sonntag.eu, diana.sonntag@medma.uniheidelberg.de

\begin{abstract}
Objective The increasingly high levels of overweight and obesity among the workforce are accompanied by a hidden cost burden due to losses in productivity. This study reviews the extent of indirect cost of overweight and obesity.

Methods A systematic search was conducted in eight electronic databases (PubMed, Cochrane Library, Web of Science Core Collection, Psychlnfo, Cinahl, EconLit and ClinicalTrial.gov). Additional studies were added from reference lists of original studies and reviews. Studies were eligible if they were published between January 2000 and June 2017 and included monetary estimates of indirect costs of overweight and obesity. The authors reviewed studies independently and assessed their quality. Results Of the 3626 search results, 50 studies met the inclusion criteria. A narrative synthesis of the reviewed studies revealed substantial costs due to lost productivity among workers with obesity. Especially absenteeism and presenteeism contribute to high indirect costs. However, the methodologies and results vary greatly, especially regarding the cost of overweight, which was even associated with lower indirect costs than normal weight in three studies.

Conclusion The evidence predominantly confirms substantial short-term and long-term indirect costs of overweight and obesity in the absence of effective customised prevention programmes and thus demonstrates the extent of the burden of obesity beyond the healthcare sector.
\end{abstract}

\section{INTRODUCTION}

The obesity epidemic has become a global public health concern. ${ }^{1}$ The rising rates of overweight and obesity are accompanied in adulthood by a higher risk of type 2 diabetes, hypertension, coronary heart disease and stroke, ${ }^{2}$ which cause substantial healthcare costs. In 2008, the estimated annual medical cost of obesity in USA was US $\$ 147$ billion due to $42 \%$ higher medical spending per capita. ${ }^{3}$ USA has significantly high obesity costs and other countries also struggle with substantial overweight-related and obesity-related medical costs; Germany, for example, had costs of $\$ 9.2$ billion in 2008. ${ }^{4}$ The rising prevalence of overweight

\section{Strengths and limitations of this study}

- It presents results on all major indirect costs categories such as absenteeism, presenteeism, disability, premature mortality and worker compensation from 50 studies and discusses the issue of causality.

- It assesses comprehensively the monetary value of the indirect costs of overweight and obesity which allows (inter-)national comparisons among all indirect cost categories. This in turn gives policymakers and intervention developers the basis they need to make informed decisions on (re-)allocating resources to address those cost categories with the highest burden.

- It applies an extensive quality assessment of approaches, methods and estimates of indirect costs of overweight and obesity which helps to better understand the utility and applicability of included cost-of-illness studies.

- Due to diverging body mass index groups and indirect cost categories among the studies included, a graphical comparison of the average costs per person or per country of each study was conducted (instead of a meta-analysis).

- Publication bias (whereby positive studies are more likely to be published than negative ones) and selection bias (exclusion of studies written in languages other than English or German) limit the generalisability of the findings of this review.

and obesity is also related to indirect costs resulting from morbidity and mortality. ${ }^{5-7}$ Indirect costs are defined as the losses from reduced work productivity due to short-term and long-term inability to work. In particular, obesity is associated with an increased risk of temporary work loss such as sick leave (absenteeism) and reduced productivity while being present at work (presenteeism). It is also associated with permanent work loss, which includes disability pension and premature death. ${ }^{5}$ Indeed, recent reviews have found strong evidence that temporary and permanent work loss attributable to obesity result in a substantial burden for national health and insurance pension systems. ${ }^{89}$ 
While a number of systematic reviews have analysed lost productivity of overweight and obesity among workers, their range is relatively narrow. For example, several do not include the monetary value of the indirect costs, ${ }^{5-7} 10$ while others focus only on the combined direct and indirect costs of obesity. ${ }^{10}$ Similarly, a few limit their range by concentrating on specific countries ${ }^{912}$ or specific cost categories such as absenteeism and disability. ${ }^{5-710}$ Indeed, only one review provides a more extensive overview of the economic consequences of absenteeism, presenteeism, disability, premature mortality and worker compensation costs. ${ }^{13}$ Yet even this review does not comprehensively assess the monetary value of indirect costs or provide a quality assessment of the included studies. However, it does identify several weaknesses among the included studies (eg, paucity of both longitudinal studies and presenteeism assessments as well as the need for monetary values of missed work).

Our review addresses the shortcomings of previous systematic reviews and includes studies which acknowledge the research gaps noted by Trogdon et al. ${ }^{13}$ With its broad range, our review is the only international review that presents an extensive comparison of the monetary consequences of all indirect cost categories. We systematically review and critically assess both the current evidence for each type of indirect costs and the methodology and research design used. In addition, we address briefly the question of causality between obesity and costs.

\section{METHODS}

This review was conducted according to the Centre for Reviews and Dissemination guidance for undertaking reviews in healthcare. ${ }^{14}$

\section{Search strategy}

In cooperation with a Cochrane expert from the University Library of Heidelberg, we developed a search strategy to identify all published studies on the indirect costs of overweight and obesity. A keyword search was carried out using the following electronic databases and study registers from inception to June 2017: PubMed, Cochrane Library, Web of Science Core Collection, PsychInfo, Cinahl, EconLit and ClinicalTrial.gov. The search terms and the search strategy are outlined in online supplementary supporting information 1 and 2.

\section{Inclusion and exclusion criteria}

Studies were included if they contained a monetary estimate of the indirect costs of overweight and obesity. Indirect costs were defined as costs of overweight and obesity on labour market outcomes (absenteeism, presenteeism, short-term and long-term disability, premature death). We excluded studies, which were published in languages other than English or German, located in a developing country due to substantial differences in labour markets or connected to other illnesses. We decided to exclude studies published before 2000 because of the rising prevalence of overweight and obesity in the last few decades, ${ }^{1}$ which led to significant increases of macroeconomic costs. Instead, we placed our focus on recent results, which have not been covered in previous systematic reviews. Furthermore, only peer-reviewed studies with a full-text available were included.

\section{Study selection procedure and data extraction}

Two reviewers independently applied the inclusion and exclusion criteria. All studies underwent a title and abstract screening, and potentially relevant citations were additionally checked in a full-text screening. Disagreements were resolved through discussion and reasons for exclusion recorded. Finally, 50 studies were identified as eligible. The PRISMA diagram (figure 1) illustrates the study selection process. Data extracted included study design, target population, time horizon, effect groups, cost category and measurement and background characteristics such as authors and years of study and publication. Costs were first inflated to 2016 rates using country-specific gross domestic product inflators from the Organisation for Economic Co-Operation and Development (http://stats.oecd.org) and then converted to December 2016 US dollars. The third step was to multiply them with their respective power purchasing parity (PPP) value to achieve a comparable overview. If the year of costing was missing, the authors of the cost-of-illness (COI) study were contacted by email.

\section{Quality assessment}

In the absence of a checklist for COI studies, we conducted a quality assessment by adapting the checklist by Stuhldreher and co-authors, which evaluates the quality of COI studies. ${ }^{15}$ We assessed the following items: scope, general economic characteristics, calculation of costs, study design and analyses and presentation of results (see online supplementary supporting information 3). Two authors performed the assessment independently. All discrepancies and uncertainties were resolved through consensus.

\section{RESULTS}

We identified 3626 articles from the database searches. Title and abstract screening reduced these further to 281 studies, which were retrieved in full text. Reviewing reference lists of relevant papers, studies and systematic reviews added four potentially relevant studies (figure 1 ). Following full-text review, we excluded 231 of these studies, leaving 50 studies to be included in the review.

\section{General characteristics of the studies}

There was a wide variety among the included studies in terms of costs, target population and methodology. Online supplementary supporting information 4 shows the sample, methodology, quality and results of the studies. Most studies were conducted in USA (27), followed by Germany (8), Canada (5), Australia (2), Sweden (2), 


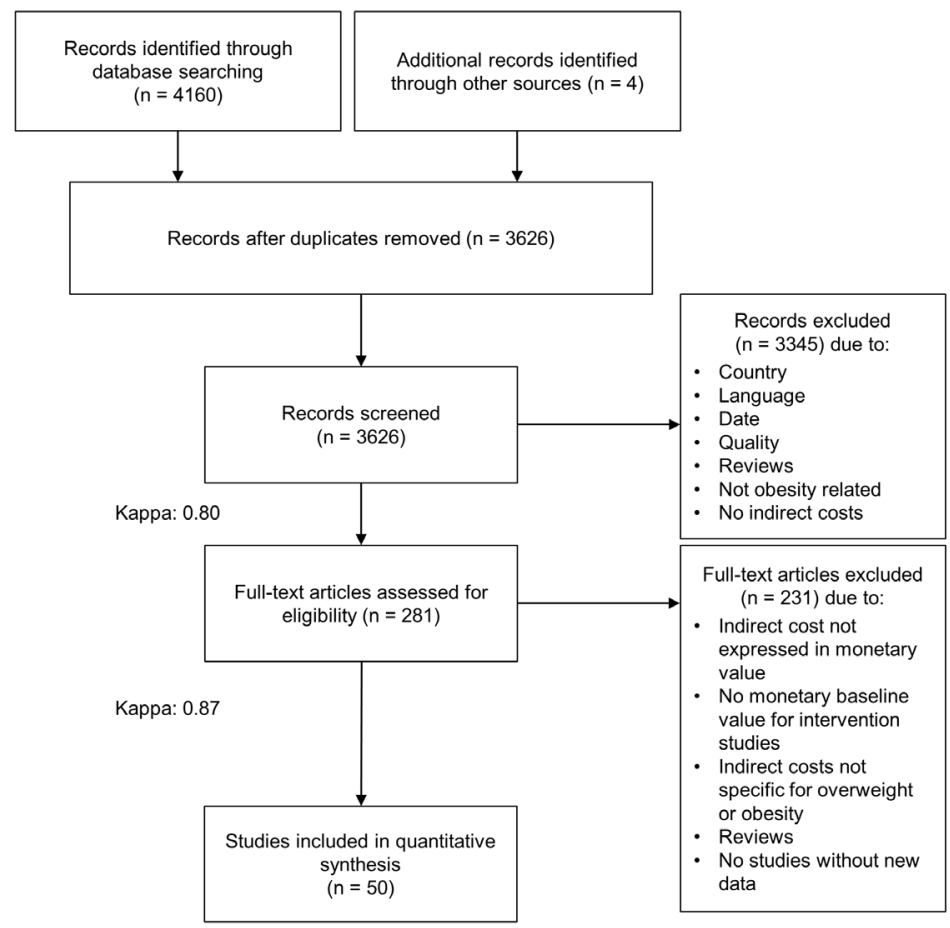

Figure 1 PRISMA flow diagram.

Finland (1), Korea (1), New Zealand (1) and the Netherlands (1). Two studies were multicountry (one covering Ireland and Northern Ireland; the other covering France, Germany, Italy, Spain and UK). For cost estimations, a microeconomic or a macroeconomic approach was applied. While the macroeconomic approach captured the national economic loss of resources measured as national cost, the microeconomic approach measured indirect costs that occur per capita or per employee. More specifically, most studies assessed the costs of absenteeism, presenteeism, short-term and long-term disability and premature death. Only five ${ }^{16-20}$ included insurance claims, such as indemnity claims, workers' compensation and other microeconomic costs related to recruitment, training, traffic, nursing or injuries. The majority of the studies included the costs of more than one of these cost categories.

Both the human capital approach (HCA) and the friction cost method (FCM) were used to calculate productivity losses. The HCA estimates costs based on the lost productivity of one individual, for example, the entire working time lost due to early retirement. The FCM only estimates the value of productivity lost until the employee is replaced. For example, if a worker goes into early retirement, the FCM would only count the period of working time lost until the worker is replaced. ${ }^{1921}$

The effect measure was exclusively the body mass index (BMI). BMI cut-off points were based on standard WHO recommendations (overweight: $25.0 \leq \mathrm{BMI} \leq 29.9$, class I obesity: $30.0 \leq \mathrm{BMI} \leq 34.9$, class II obesity: $35.0 \leq \mathrm{BMI}$ $\leq 39.9$ and class III obesity: BMI $\geq 40.0$ ), with the exception of seven studies. ${ }^{17} 18$ 22-26 Few studies estimated indirect costs due to obesity-related comorbidities. ${ }^{20}{ }^{22} 24-36$ Some controlled for physical and psychological comorbidities in regression analyses ${ }^{35}$ 37-41 or created subgroups for the costs of additional, related diseases. ${ }^{18404243}$

Online supplementary supporting information 4 displays the search results grouped by methodology into cross-sectional, longitudinal, population attributable risk and modelling studies. The majority were cross-sectional studies, which focused on annual per capita costs by assessing the overweight and obesity prevalence at a specific point in time. Longitudinal studies evaluated excess weight over a timespan of $4^{44}$ to 38 years. ${ }^{21}$ The attributable risk studies applied the population attributable fraction (PAF) method to estimate national costs. Only one study modelled the future costs of overweight and obesity based on disease prevalence among teenagers. ${ }^{45}$ Eight studies were categorised separately as 'other studies', which were not as representative. This category includes one intervention analysis ${ }^{34}$ and studies with non-representative samples, such as bariatric surgery eligible patients, ${ }^{24} 256$ military participants, ${ }^{35} 47$ parents of children with overweight or obesity ${ }^{22}$ and hospital staff working with patients with obesity. ${ }^{26}$

\section{Quality assessment}

The quality of the included studies was quite diverse (see online supplementary supporting information 3). Overall, the majority of studies met $75 \%$ of quality criteria. Three studies met all criteria. ${ }^{162} 33$ Walden et al received the lowest quality score. This study focused primarily on 


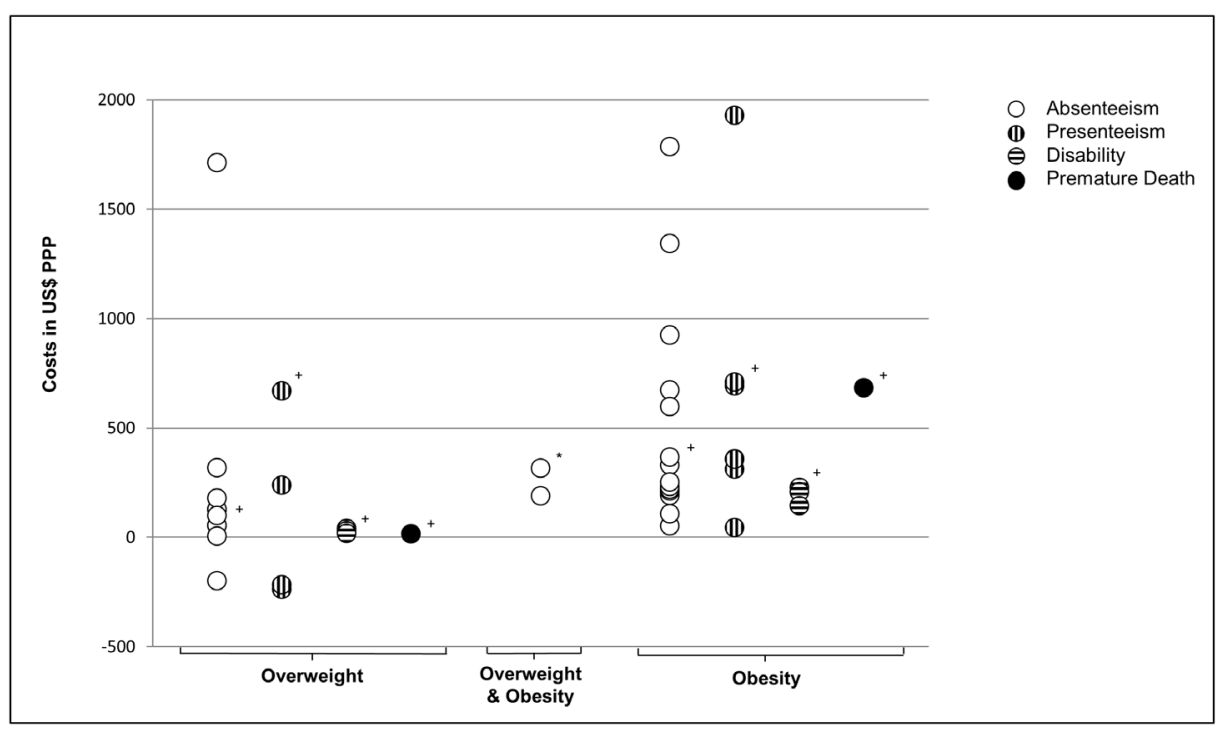

Figure 2 Microeconomic excess cost of overweight and obesity. ${ }^{+}$Adapted productivity losses per person, ${ }^{51}$ with no information on costs of normal weight. *Adapted indemnity claims cost per 100 full-time equivalents $1997-2004,{ }^{20}$ with no information on costs of normal weight.Excess per capita costs are displayed for each cost category for overweight, obesity and excess weight. Mean costs were estimated for studies which only had sex or obesity-grade specific costs available. If not available, excess costs were calculated by subtracting the cost of normal weight from overweight or obesity costs. The figure shows that the costs of obesity are significantly higher than those of overweight alone and those of overweight and obesity combined. Interestingly, the cost of overweight is not necessarily higher than the cost of healthy weight. Absenteeism and presenteeism were considerably higher and more commonly assessed than disability and premature death.

the prevention of injuries rather than on the costs of excess weight and thus did not include information on discounting, SD and cost perspective and valuation. ${ }^{26}$

Criteria regarding introduction, discussion and conclusion were mostly fulfilled. Quality was lacking in the categories 'calculation of costs', 'presentation of results' and 'study design and analysis'. Fourteen studies did not state from what perspective they calculated the costs and only included one cost category. ${ }^{17} 18202628$ 34-36 42 44 47-50 Study design and analysis were not fulfilled as over half of the studies did not report a sensitivity analysis and lacked information on the proportion of missing data or the imputation method. Furthermore, sample sizes and demographics were not always presented and only 29 studies provided SD or CIs of their results.

\section{Microeconomic findings}

The cross-sectional and longitudinal studies mostly focused on the per capita or per employee indirect costs of overweight and obesity. Figure 2 displays excess cost (defined as the additional costs of overweight and obesity compared with normal weight) by weight category due to absenteeism, presenteeism and disability. All microeconomic and macroeconomic results in this review are presented in US\$PPP and estimate the annual indirect costs unless stated otherwise. One study ${ }^{21}$ presented lifetime costs of overweight and another calculated the costs for a 10 -year period. ${ }^{39}$ One cost analysis study did not focus on productivity loss but analysed the injury costs among hospital staff attributable to heavy patients. ${ }^{26}$ As shown in figure 2 , the costs for absenteeism range from $-\$ 200^{31}$ to $\$ 1724^{30}$ for overweight and from $\$ 108^{43}$ to $\$ 1857^{30}$ for obesity. While this shows that obesity is constantly associated with productivity costs, it also displays the divergence of the results. We will present the results for each cost category in detail in the following section.

\section{Absenteeism}

Defined as time away from work due to overweight and obesity, absenteeism was probably due to ease of measurement, the most common measure of indirect costs. The majority of studies (39 out of the 50 included ones) assessed the annual costs of short-term sick leave from work by comparing sick leave days of employees with normal weight with sick leave days of employees with overweight and obesity. The excess costs of overweight were estimated to be between $\$ 54^{51}$ and $\$ 161^{31}$ and the obesity-related costs between $\$ 89^{42} 52$ and $\$ 1586 .^{53}$ The suggestions of Durden $e t$ al were significantly higher for both overweight $(\$ 1738)$ and obesity $(\$ 1857) .{ }^{30}$ By contrast, 
other studies did not use an excess-cost approach but calculated the total yearly expenses due to absenteeism for normal, overweight and obesity samples. The cost for overweight ranged from $\$ 29$ to $\$ 5132^{23} 3233414354$ and $\$ 57$ to $\$ 6759$ for obesity per person. ${ }^{18} 23323541444654$

In one study, the costs associated with healthy weight (\$294) were higher than overweight (\$94) but lower than the costs for obesity (\$402) ${ }^{43}$ Three studies assessed the costs for men and women separately. For women with obesity, the cost was between $\$ 170$ and $\$ 1391$, which was higher than the cost for men with obesity $(\$ 89-$ \$1130). ${ }^{31} 4252$ Gussenhoven et al and Kyröläinen et al estimated the costs of excess weight $($ BMI $>25)$ between $\$ 915^{47}$ and $\$ 4307 .^{34}$ Another study assessed the relationship between children with overweight or obesity and parental work absence and found that while the cost (\$142) for children with obesity was higher than the cost of healthy weight children $(\$ 120)$, the cost of children with overweight was lower $(\$ 102) .{ }^{22}$

Wolfenstetter assessed weight changes over 10 years and the related costs per group and found that the cost of a person with overweight or obesity is higher than the economic loss of a healthy weight or previously healthy weight person. ${ }^{36}$ Neovius et al also applied a longitudinal approach with data from 1969 and a 38-year follow-up. They estimated lifetime productivity losses of $\$ 18064$ using the HCA (FCM: \$12 995) for overweight and \$19390 (FCM: \$14 317) for obesity. ${ }^{21}$ Another long-term study evaluated the yearly cost of a 20000 workforce over 30 years at $\$ 6.6$ million. ${ }^{28}$

\section{Presenteeism}

Nine studies included the effect of reduced productivity at work (presenteeism) due to overweight or obesity, which was assessed by using an employee survey. ${ }^{31-33} 384144464851$ While costs due to presenteeism among individuals with overweight ranged between $-\$ 611^{31}$ and $\$ 1669,{ }^{33}$ costs among individuals with obesity were between $\$ 11^{46}$ and $\$ 4175 .^{31}$ Surprisingly, in Peake's study, the cost of presenteeism among employees with overweight $(\$ 474)$ was lower than for individuals with normal weight (\$695). ${ }^{35}$ Similarly, Finkelstein et al estimated lower costs among men with overweight compared with men with normal weight. ${ }^{31}$ The excess cost of obesity ranged from $\$ 429$ to $\$ 4175$ for men and from $\$ 927$ to $\$ 3341$ for women. ${ }^{31}$ Another study by Finkelstein et al measured the quarterly indirect costs of bariatric surgery patients to be $\$ 11 .^{46}$ The cost of moderate or extreme obesity was estimated to be $\$ 699,{ }^{51} \$ 1684,{ }^{33} \$ 1990^{32}$ and $\$ 24144^{45}$ Peake and co-authors differentiated between the cost of having a BMI higher than 30 with restricted body fat $(\leq 28 \%$ for females, $\leq 24 \%$ for males) (\$1129) and having a BMI higher than 30 without body fat restriction $(\$ 984) .^{35}$

One study calculated the combined costs of absenteeism and presenteeism. The combined costs were $\$ 5515$ for overweight and from $\$ 6402$ to $\$ 9104$ for obesity classes I-III. $^{40}$
Insurance claims

Insurance claims were measured as indemnity claims ${ }^{20}$ or workers' compensation expenditures due to work absence. ${ }^{1618}$ The only study which exclusively assessed insurance claims estimated indemnity claim costs at $\$ 189$ per full-time equivalent. ${ }^{20}$ For workers' compensation, the additional costs of overweight were estimated to be $\$ 180$ and the additional costs for obesity classes I-III ranged from $\$ 525$ to $\$ 707 .{ }^{16}$ Kleinman et al assumed the costs of overweight at $\$ 63$ and those of obesity at $\$ 105$. $^{18}$

\section{Short-term and long-term disability}

Four studies considered costs of lost productivity due to short-term and long-term disability. ${ }^{16214651}$ While excess costs due to disability were estimated to range from $\$ 30^{16}$ to $\$ 41^{51}$ among individuals with overweight, obesity was associated with costs between $\$ 21$ and $\$ 439 .^{51}$ Kleinman et al estimated $\$ 158$ for overweight and $\$ 242$ for obesity. ${ }^{18}$ The lifetime cost of disability and disability pensions varied substantially depending on methodology; while estimations of cost based on the HCA varied between \$31 037 (overweight) and \$32 668 (obesity), estimations of cost based on the FCM were \$2649 (overweight) and $\$ 3115$ (obesity). ${ }^{21}$

\section{Premature mortality}

Work loss due to early mortality was assessed by two studies. ${ }^{21}{ }^{51}$ Excess productivity costs related to these indirect costs were $\$ 29$ for overweight and from $\$ 212$ to $\$ 1170$ for grade I-III obesity. ${ }^{51}$ Neovius et al calculated the lifetime productivity losses and found $\$ 87184$ (HCA) or \$20 066 (FCM) for overweight and \$114 626 (HCA) or $\$ 23070$ (FCM) for obesity. ${ }^{21}$

\section{Macroeconomic findings}

Among the studies focusing on macroeconomic costs, all but two focused on national costs for 1 year and found costs ranging from $\$ 79$ million in New Zealand ${ }^{19}$ to $\$ 41$ billion for three US states. ${ }^{48}$ Figure 3 displays the national costs per country and online supplementary supporting information 5 shows per capita estimates of the macroeconomic findings. Knoll and Hauner estimated that the cost of obesity would increase from $\$ 1.8$ billion in 2003 to $\$ 3.6$ billion in $2020 .{ }^{49}$ Lightwood and co-authors estimated future costs in USA on current adolescent obesity and proposed a rise in costs from $\$ 954$ million in 2020 to $\$ 36$ billion in $2050 .{ }^{45}$

The majority of the PAF studies included costs of absenteeism, disability and premature death (for detailed information, see online supplementary supporting information 4). The PAF approach indicates the aetiological fraction of morbidity and mortality of disease prevalence caused by a risk factor (see equation 1 ):

$$
\mathrm{PAF}=\frac{\sum_{\mathrm{i}=1}^{\mathrm{n}} \mathrm{P}_{\mathrm{i}} \mathrm{RR} R_{\mathrm{i}}-\sum_{\mathrm{i}=1}^{\mathrm{n}} \mathrm{P}_{\mathrm{i}}^{\prime} \mathrm{RR}_{\mathrm{i}}}{\sum_{\mathrm{i}=1}^{\mathrm{n}} \mathrm{P}_{\mathrm{i}} \mathrm{RR} \mathrm{R}_{\mathrm{i}}}
$$

$P_{i}=$ proportion of population at exposure level $i$, current exposure, 


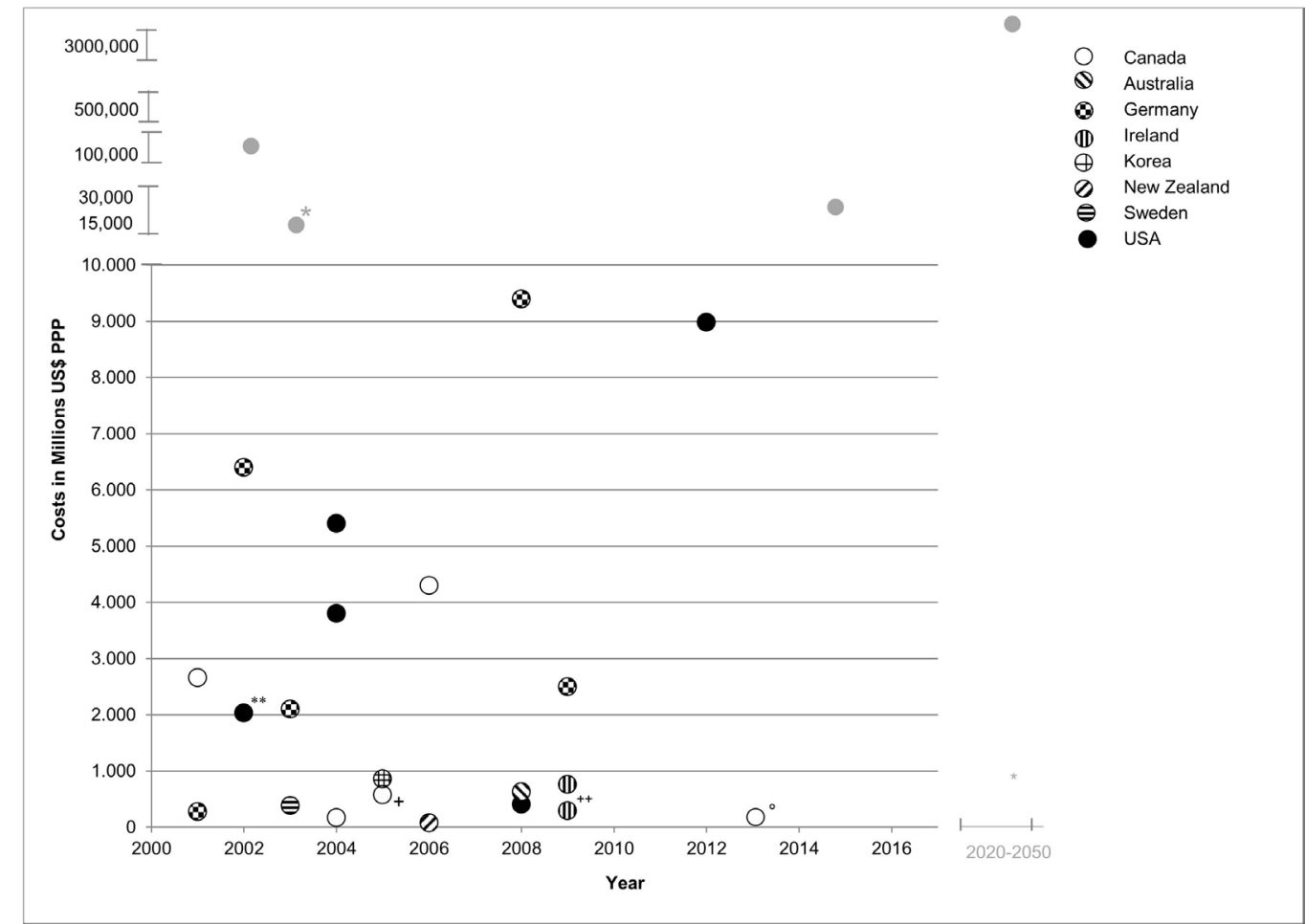

Figure 3 Macroeconomic costs of overweight and obesity. Ricci and Chee, ${ }^{38}$ Lightwood et al ${ }^{45}$ and Chenoweth and Leutzinger ${ }^{48}$ are outliers (coloured in grey). ${ }^{*}$ Costs of the three US states: California, North Carolina, Massachusetts. ${ }^{+}$Costs of the province Alberta. ${ }^{* \star}$ Costs of the state New Mexico. ${ }^{++}$Costs of South Plains of Texas.Almost analogous to country size and high prevalence rates, USA has the highest national costs. Its lower values are related to particular states. The lowest costs were found in 2006 in New Zealand. National costs seem to increase in future years.

$P_{i}^{\prime}=$ proportion of population at exposure level $i$, counterfactual or ideal level of exposure,

$R R=$ the relative risk at exposure level $i$, $\mathrm{n}=$ the number of exposure levels.

More specifically, there is strong evidence for higher risk of comorbidities such as type 2 diabetes, hypertension, coronary heart disease and stroke in individuals with overweight and obesity. ${ }^{556}$ Since overweight and obesity cause only a fraction of comorbidity-related costs, multiplying the PAF by the costs of each comorbidity and then summing up across all diseases estimates total obesity-attributable costs.

Five studies assessed the costs of excess weight in Germany. ${ }^{49} 5057$ Lehnert et al estimated the costs at $\$ 9.5$ billion, ${ }^{4}$ Konnopka et al at $\$ 6.5$ billion $^{57}$, Knoll and Hauner at $\$ 1.8$ billion $^{49}$ and Sander and Bergemann at $\$ 282$ million. ${ }^{50}$ The costs for Canada were suggested to be $\$ 2.7$ billion by Katzmaryk and Janssen, ${ }^{58} \$ 4.4$ billion by Anis $e$ t $a \tilde{l}^{\tilde{9}}$ and $\$ 534$ million (for Alberta only) by Moffatt et $a l^{60}$ The economic loss for the Ireland was between $\$ 767$ million (FCM) and \$840million (HCA). For Northern Ireland, the cost was proposed to be between \$294 million (FCM) and \$491 million (HCA) ${ }^{61}$ In addition to costs of absenteeism and premature death, Lal et al assessed training and recruitment costs for New Zealand and suggested a national loss between $\$ 79$ million (FCM) and $\$ 180$ million (HCA).$^{19}$ In Korea, the productivity loss of excess weight was proposed to be at $\$ 872$ million due to premature death, hospital admission, nursing costs and fees and transportation costs. ${ }^{17}$ The economic loss associated with excess weight in Australia was estimated to be at $\$ 637$ million. ${ }^{62}$ For three US states (California, North Carolina, Massachusetts), Chenoweth and Leutzinger assumed a productivity loss of $\$ 41$ billion. $^{48}$

While the majority applied the PAF approach, 12 studies assessed the national costs based on lost workdays due to work absence, loss of productivity and premature death. ${ }^{24} 2527293738425263-66$ Eight studies assessed the economic loss in USA. The costs for obesity were estimated to be $\$ 11.3$ billion by Asay et $a l,{ }^{66} \$ 171$ million for grade III obesity by Klarenbach $e t a l,{ }^{63}$ and $\$ 3.8$ billion due to non-diabetic and morbidly obese by Cawley et al. ${ }^{42}$ The costs of obesity were assessed at $\$ 5.5$ billion $^{52}$ by Cawley and co-authors and $\$ 9$ billion by Andreyeva et al27. Ricci and Chee were the only ones to consider the excess costs of absenteeism and presenteeism in the United States, which they estimated to be $\$ 15.7$ billion for obesity. The costs of overweight and normal weight did not differ significantly. ${ }^{40}$ Two studies focused on the economic loss due to obesity in specific US regions ( $\$ 409$ million in a region of Texas ${ }^{30}$ and $\$ 2$ billion in the state of New Mexico $\left.{ }^{32}\right)$. One study estimated the costs for the province of Quebec in Canada at $\$ 531$ million. ${ }^{65}$ For Germany, the cost of overweight and obesity was $\$ 2.5$ billion according to a study by Lehnert et al37, and $\$ 5$ billion according to a later study by Effertz et al. ${ }^{64}$ Economic loss due to 
premature death was estimated for Sweden at $\$ 4.8$ million for overweight and $\$ 383$ million for obesity. ${ }^{28}$

\section{DISCUSSION}

This review assessed 50 COI studies on the indirect costs of overweight and obesity. The studies applied various methodologies and were mostly of good quality. Although the results varied, most studies found that excess weight entailed substantial indirect costs. While the cost category primarily considered was sick leave, there was also frequent assessment of presenteeism, disability and premature death. Compared with employees with normal weight, individuals with obesity missed more time from work and worked less productively, resulting in higher indirect costs. Even if the literature suggests substantial indirect costs of overweight and obesity, the results should be interpreted with caution.

Our findings identify and underscore the large variety in defining and measuring the indirect costs of overweight and obesity. Indeed, this large variety made it difficult to provide an estimate of these indirect costs. Moreover, these costs differ substantially due to dissimilar methodological approaches (eg, HCA vs FCM) and varying analytic methods (eg, simulation-based vs regression-based models) (see online supplementary supporting information 4). This is especially true of excess indirect costs of overweight, which range between $-517 \mathrm{US} \$ \mathrm{PPP}^{31}$ and 3271 US $\$ P P P .{ }^{30}$ These methodological differences, in turn, hamper the comparability of cost estimations of overweight and obesity.

The heterogeneity of the results raises the question whether the cost estimates correctly reflect the actual indirect costs of overweight and obesity. Most of the included studies used a top-down approach, which is usually easier to carry out as it is based on secondary data and thus requires only few country-specific estimates. However, in contrast to the bottom-up approach, it often relies on high-level aggregation and approximation of service costs and may also suffer from double-counting of resources. Moreover, the top-down approach does not take account of multiple obesity-attributable diseases (eg, type 2 diabetes and coronary heart disease) and their interactions, which may lead to biased (usually upwards) results. $^{67}$

Furthermore, the comprehensiveness of costs included in an analysis affects the reliability of the final result. If indirect costs consist of absenteeism costs alone, they will differ from indirect costs due to absenteeism and presenteeism combined. Additional workplace costs, such as transport costs and special training for hospital staff, together with non-monetary costs (eg, quality-of-life losses) were included in a minority of the studies. Differences in indirect costs of overweight and obesity in the workplace can partly be explained by individual incomes. Individual wages (only captured by Kleinman et $a l^{18}$ ) consider occupation-specific incomes and the fact that women with overweight and men with obesity earn lower wages than normal-weight workers. ${ }^{689}$ Most of the assessed COI studies calculated indirect costs based on estimations of the income of employees. These heterogeneous estimations of cost may be partly explained by occupation-specific incomes and different wage estimates (range: $\$ 6$ per hour ${ }^{63}$ to $\$ 500$ daily wage ${ }^{44}$ ).

Besides costs measured by income in workplace-related productivity losses, costs from unpaid work can occur. In our review, one study examined costs from unpaid work and found that reduced household production activities of caregivers cause sizeable indirect costs comparable with those of paid work. ${ }^{58}$ Moreover, this cost category is also important as the prevalence of childhood overweight and obesity has increased dramatically during the past few years, confronting (grand)parents and caregivers with time losses from unpaid work. A longer measurement period may influence the accuracy of the assessed costs. Two of the studies reviewed considered the impact of childhood overweight and obesity. ${ }^{22}{ }^{45}$ Lightwood et al recorded a long timeframe including indirect costs from adolescence and calculated high indirect costs of excess weight for future years. ${ }^{45}$

Finally, the lack of evidence for the causal link between obesity and productivity loss has been noted in previous reviews. 5613 Recent studies have tried to address this shortcoming by applying longitudinal study designs and controlling for confounding factors, including sociodemographic and work-related and health-related covariates. $^{213744}$ However, all these studies assume that obesity is a direct cause of productivity loss and may thus overestimate the effect on indirect cost. None of them comprehensively address the question, together with associated statistical challenges, whether obesity could also serve as a biological mediator on the causal pathway or an effect modifier. Indeed, obesity may act both as direct explanatory variable and mediator when studying the relationship between cardiorespiratory fitness and productivity loss due to increased metabolic syndrome. ${ }^{70}$ Additionally, obesity could also serve as an effect modifier as different levels of obesity modify the association between cardiorespiratory fitness and productivity loss. Moreover, the loss of productivity with increasing BMI declines with age as a higher BMI tends to be protective (eg, reduced bone density loss and osteoporosis). ${ }^{71} 72$

Clearly, a causal framework for a meaningful assignment of indirect costs of obesity requires establishing whether obesity acts as a cause, a mediator or an effect modifier. More specifically, prospective analyses are urgently needed to determine the time of occurrence, that is, whether diseases occur before (after) an individual has become overweight or obese. Together with such prospective analyses, valid measurements of productivity losses have to be developed and new studies initiated which measure productivity among employees before and after an effective obesity intervention. Only then can there be a successful application of more sophisticated econometric models. 
Overall, most studies met most of the quality criteria but could be improved in three major areas. First, the scope could be increased by including more than one cost category. Second, estimations of cost would be more accurate if they included obesity-related diseases and were based on individual income. Third, the reliability of long-term economic consequences would be improved by taking childhood obesity into account. To translate lifetime consequences of childhood obesity into economic calculations, it is important to develop dynamic models of obesity-related productivity losses projected over a timeframe longer than the 1 year period usually used in costof-obesity estimations. ${ }^{73} 74$

One limitation of this review is the potential publication bias, whereby positive studies are more likely to be published than negative studies. For instance, 47 out of the 50 included studies reported higher costs of overweight and obesity. While all studies reported higher costs of obesity, three studies found lower costs of overweight compared with normal weight. Furthermore, due to financial and time restraints, we could only include studies published in English and German, which may result in a selection bias. However, our findings include results from 11 countries and regions which are neither English-speaking nor German-speaking.

The included studies exhibited methodological inconsistencies and varying levels of quality. Nevertheless, they consistently confirm that overweight and obesity have substantial short-term and long-term indirect costs both on the microeconomic and macroeconomic level. Consequently, an increase in public health initiatives, together with effective company weight-loss programmes, could considerably improve the productivity of workers currently overweight or obese.

Acknowledgements We thank Mauritius Grilli for developing our search strategy and conducting systematic search in electronic databases, Isabelle Hofmann for support in title and abstract screening, Tanja-Maria Kessel and Franziska Wagner for support in screening, data extraction and writing and Susan Sills for excellent language editing.

Contributors DS conceived the study and wrote the first draft of an earlier version. $A G$ and $A G$ performed the literature search and data extraction. All authors analysed the data and were involved in writing the paper and had final approval of the submitted and published version.

Funding This work was supported by the Olympia-Morata-Program of Heidelberg University, which had no further role in the study design; in the collection, analyses and interpretation of data; in writing the report; and in the decision to submit the paper for publication. Furthermore, we acknowledge the financial support of the Deutsche Forschungsgemeinschaft and Ruprecht-Karls-Universität Heidelberg within the funding programme Open Access Publishing.

Competing interests None declared.

Provenance and peer review Not commissioned; externally peer reviewed.

Data sharing statement All unpublished data are only available to the authors.

Open Access This is an Open Access article distributed in accordance with the Creative Commons Attribution Non Commercial (CC BY-NC 4.0) license, which permits others to distribute, remix, adapt, build upon this work non-commercially, and license their derivative works on different terms, provided the original work is properly cited and the use is non-commercial. See: http://creativecommons.org/licenses/by-nc/4.0/ (c) Article author(s) (or their employer(s) unless otherwise stated in the text of the article) 2017. All rights reserved. No commercial use is permitted unless otherwise expressly granted.

\section{REFERENCES}

1. Raine KD, Nykiforuk Cl, Vu-Nguyen $\mathrm{K}$, et al. Understanding key influencers' attitudes and beliefs about healthy public policy change for obesity prevention. Obesity 2014;22:2426-33.

2. Field AE, Coakley $E H$, Must $A$, et al. Impact of overweight on the risk of developing common chronic diseases during a 10-year period. Arch Intern Med 2001;161:1581-6.

3. Finkelstein EA, Trogdon JG, Cohen JW, et al. Annual medical spending attributable to obesity: payer-and service-specific estimates. Health Aff 2009;28:w822-w831.

4. Lehnert T, Streltchenia P, Konnopka A, et al. Health burden and costs of obesity and overweight in Germany: an update. Eur J Health Econ 2015;16:957-67.

5. Neovius K, Johansson K, Rössner S, et al. Disability pension, employment and obesity status: a systematic review. Obes Rev 2008;9:572-81.

6. Neovius K, Johansson K, Kark M, et al. Obesity status and sick leave: a systematic review. Obes Rev 2009;10:17-27.

7. van Duijvenbode DC, Hoozemans MJ, van Poppel MN, et al. The relationship between overweight and obesity, and sick leave: a systematic review. Int J Obes 2009;33:807-16.

8. Lehnert T, Sonntag D, Konnopka A, et al. Economic costs of overweight and obesity. Best Pract Res Clin Endocrinol Metab 2013;27:105-15.

9. von Lengerke $\mathrm{T}$, Krauth $\mathrm{C}$. Economic costs of adult obesity: a review of recent European studies with a focus on subgroup-specific costs. Maturitas 2011;69:220-9.

10. Specchia ML, Veneziano MA, Cadeddu C, et al. Economic impact of adult obesity on health systems: a systematic review. Eur J Public Health 2015;25:255-62.

11. Dee A, Kearns K, O'Neill C, et al. The direct and indirect costs of both overweight and obesity: a systematic review. BMC Res Notes $2014 ; 7: 242$.

12. Janssen I. The public health burden of obesity in Canada. Can J Diabetes 2013;37:90-6.

13. Trogdon JG, Finkelstein EA, Hylands T, et al. Indirect costs of obesity: a review of the current literature. Obes Rev 2008;9:489-500.

14. University of York Centre for Reviews and Dissemination. Systematic reviews: $C R D$ 's guidance for undertaking reviews in health care: University of York, Centre for Reviews \& Dissemination, 2009.

15. Stuhldreher N, Konnopka A, Wild B, et al. Cost-of-illness studies and cost-effectiveness analyses in eating disorders: a systematic review. Int J Eat Disord 2012;45:476-91.

16. Henke RM, Carls GS, Short ME, et al. The relationship between health risks and health and productivity costs among employees at Pepsi Bottling Group. J Occup Environ Med 2010;52:519-27.

17. Kang JH, Jeong BG, Cho YG, et al. Socioeconomic costs of overweight and obesity in Korean adults. J Korean Med Sci 2011;26:1533-40.

18. Kleinman N, Abouzaid S, Andersen L, et al. Cohort analysis assessing medical and nonmedical cost associated with obesity in the workplace. J Occup Environ Med 2014;56:161-70.

19. Lal A, Moodie M, Ashton T, et al. Health care and lost productivity costs of overweight and obesity in New Zealand. Aust N Z J Public Health 2012;36:550-6.

20. Ostbye T, Dement JM, Krause KM. Obesity and workers' compensation: results from the duke health and safety surveillance system. Arch Intern Med 2007;167:766-73.

21. Neovius K, Rehnberg C, Rasmussen F, et al. Lifetime productivity losses associated with obesity status in early adulthood: a population-based study of Swedish men. Appl Health Econ Health Policy 2012;10:309-17.

22. Breitfelder A, Wenig CM, Wolfenstetter SB, et al. Relative weightrelated costs of healthcare use by children-results from the two German birth cohorts, GINI-plus and LISA-plus. Econ Hum Biol 2011;9:302-15.

23. Chenoweth DH, Rager RC, Haynes RG. Relationship between body mass index and workers' compensation claims and costs: results from the North Carolina league of municipalities database. $J$ Occup Environ Med 2015;57:931-7.

24. Ewing BT, Thompson MA, Wachtel MS, et al. A cost-benefit analysis of bariatric surgery on the South Plains region of Texas. Obes Surg 2011;21:644-9. 
25. Frezza EE, Wachtel MS, Ewing BT. The impact of morbid obesity on the state economy: an initial evaluation. Surg Obes Relat Dis 2006;2:504-8.

26. Walden CM, Bankard SB, Cayer B, et al. Mobilization of the obese patient and prevention of injury. Ann Surg 2013;258:1-50.

27. Andreyeva T, Luedicke J, Wang YC. State-level estimates of obesity-attributable costs of absenteeism. J Occup Environ Med 2014;56:1120-7.

28. Bhojani FA, Tsai SP, Wendt JK, et al. Simulating the impact of changing trends in smoking and obesity on productivity of an industrial population: an observational study. BMJ Open 2014;4:e004788.

29. Borg S, Persson U, Odegaard K, et al. Obesity, survival, and hospital costs-findings from a screening project in Sweden. Value Health 2005;8:562-71.

30. Durden ED, Huse D, Ben-Joseph R, et al. Economic costs of obesity to self-insured employers. J Occup Environ Med 2008;50:991-7.

31. Finkelstein EA, DiBonaventura M, Burgess SM, et al. The costs of obesity in the workplace. J Occup Environ Med 2010;52:971-6.

32. Gates DM, Succop P, Brehm BJ, et al. Obesity and presenteeism: the impact of body mass index on workplace productivity. $J$ Occup Environ Med 2008;50:39-45.

33. Goetzel RZ, Gibson TB, Short ME, et al. A multi-worksite analysis of the relationships among body mass index, medical utilization, and worker productivity. J Occup Environ Med 2010;52(Suppl 1):S52-S58.

34. Gussenhoven AH, van Wier MF, Bosmans JE, et al. Costeffectiveness of a distance lifestyle counselling programme among overweight employees from a company perspective, ALIFE@Work: a randomized controlled trial. Work 2013;46:337-46.

35. Peake J, Gargett S, Waller M, et al. The health and cost implications of high body mass index in Australian defence force personnel. BMC Public Health 2012;12:451.

36. Wolfenstetter SB. Future direct and indirect costs of obesity and the influence of gaining weight: results from the MONICA/KORA cohort studies, 1995-2005. Econ Hum Biol 2012;10:127-38.

37. Lehnert T, Stuhldreher N, Streltchenia P, et al. Sick leave days and costs associated with overweight and obesity in Germany. J Occup Environ Med 2014;56:20-7.

38. Ricci JA, Chee E. Lost productive time associated with excess weight in the U.S. workforce. J Occup Environ Med 2005;47:1227-34.

39. Su W, Huang J, Chen F, et al. Modeling the clinical and economic implications of obesity using microsimulation. $J$ Med Econ 2015;18:886-97.

40. DiBonaventura M, Lay AL, Kumar M, et al. ., The association between body mass index and health and economic outcomes in the United States. J Occup Environ Med, 2015. ;57:1047-54.

41. Gupta S, Richard L, Forsythe A. The humanistic and economic burden associated with increasing body mass index in the EU5. Diabetes Metab Syndr Obes 2015;8:327-38.

42. Cawley J, Rizzo JA, Haas K. The association of diabetes with job absenteeism costs among obese and morbidly obese workers. $J$ Occup Environ Med 2008;50:527-34.

43. Sullivan PW, Ghushchyan V, Ben-Joseph RH. The effect of obesity and cardiometabolic risk factors on expenditures and productivity in the United States. Obesity 2008;16:2155-62.

44. Kirkham HS, Clark BL, Bolas CA, et al. Which modifiable health risks are associated with changes in productivity costs? Popul Health Manag 2015;18:30-8.

45. Lightwood J, Bibbins-Domingo K, Coxson P, et al. Forecasting the future economic burden of current adolescent overweight: an estimate of the coronary heart disease policy model. Am J Public Health 2009;99:2230-7.

46. Finkelstein EA, Allaire BT, Dibonaventura MD, et al. Incorporating indirect costs into a cost-benefit analysis of laparoscopic adjustable gastric banding. Value Health 2012;15:299-304.

47. Kyröläinen $\mathrm{H}$, Häkkinen $\mathrm{K}$, Kautiainen $\mathrm{H}$, et al. Physical fitness, $\mathrm{BMI}$ and sickness absence in male military personnel. Occup Med 2008;58:251-6.

48. Chenoweth $\mathrm{D}$, Leutzinger $\mathrm{J}$. The economic cost of physical inactivity and excess weight in American adults. $J$ Phys Act Health 2006;3:148-63.
49. Knoll K-P, Hauner $\mathrm{H}$. A health-economic analysis of the total cost burden caused by obesity and the diseases associated with obesity in the Federal Republic of Germany. Adipositas 2008;2:204-10.

50. Sander B, Bergemann R. Economic burden of obesity and its complications in Germany. Eur J Health Econ 2003;4:248-53.

51. Dall TM, Fulgoni VL, Zhang Y, et al. Predicted national productivity implications of calorie and sodium reductions in the American diet. Am J Health Promot 2009;23:423-30.

52. Cawley J, Rizzo JA, Haas K. Occupation-specific absenteeism costs associated with obesity and morbid obesity. J Occup Environ Med 2007;49:1317-24.

53. Finkelstein E, Fiebelkorn IC, Wang G. The costs of obesity among full-time employees. Am J Health Promot 2005;20:45-51.

54. Tsai SP, Ahmed FS, Wendt JK, et al. The impact of obesity on illness absence and productivity in an industrial population of petrochemical workers. Ann Epidemiol 2008;18:8-14.

55. Park MH, Falconer C, Viner RM, et al. The impact of childhood obesity on morbidity and mortality in adulthood: a systematic review. Obes Rev 2012;13:985-1000.

56. Reilly JJ, Kelly J. Long-term impact of overweight and obesity in childhood and adolescence on morbidity and premature mortality in adulthood: systematic review. Int J Obes 2011;35:891-8.

57. Konnopka A, Bödemann M, König HH. Health burden and costs of obesity and overweight in Germany. Eur $\mathrm{J}$ Health Econ 2011;12:345-52.

58. Katzmarzyk PT, Janssen I. The economic costs associated with physical inactivity and obesity in Canada: an update. Can J Appl Physiol 2004;29:90-115.

59. Anis $\mathrm{AH}$, Zhang W, Bansback N, et al. Obesity and overweight in Canada: an updated cost-of-illness study. Obes Rev 2010;11:31-40.

60. Moffatt E, Shack LG, Petz GJ, et al. The cost of obesity and overweight in 2005: a case study of Alberta, Canada. Can J Public Health 2011;102:144-8.

61. Dee A, Callinan A, Doherty E, et al. Overweight and obesity on the island of Ireland: an estimation of costs. BMJ Open 2015;5:e006189.

62. Cadilhac DA, Magnus A, Sheppard L, et al. The societal benefits of reducing six behavioural risk factors: an economic modelling study from Australia. BMC Public Health 2011;11:483.

63. Klarenbach S, Padwal R, Chuck A, et al. Population-based analysis of obesity and workforce participation. Obesity 2006;14:920-7.

64. Effertz T, Engel S, Verheyen F, et al. The costs and consequences of obesity in Germany: a new approach from a prevalence and life-cycle perspective. Eur J Health Econ 2016;17:1141-58.

65. Blouin C, Hamel D, Vandal N, et al. The economic consequences of obesity and overweight among adults in Quebec. Can J Public Health 2017;107:507-e513.

66. Asay GR, Roy K, Lang JE, et al. Absenteeism and Employer Costs Associated With Chronic Diseases and Health Risk Factors in the US Workforce. Prev Chronic Dis 2016;13:E141.

67. Segel JE. Cost-of-illness studies-a primer: RTI-UNC Center of Excellence in Health Promotion Economics, 2006:1-39.

68. Han E, Norton EC, Stearns SC. Weight and wages: fat versus lean paychecks. Health Econ 2009;18:535-48.

69. Han E, Norton EC, Powell LM. Direct and indirect effects of body weight on adult wages. Econ Hum Biol 2011;9:381-92.

70. Díez-Fernández A, Sánchez-López M, Mora-Rodríguez R, et al. Obesity as a mediator of the influence of cardiorespiratory fitness on cardiometabolic risk: a mediation analysis. Diabetes Care 2014;37:855-62.

71. De Laet C, Kanis JA, Odén A, et al. Body mass index as a predictor of fracture risk: a meta-analysis. Osteoporos Int 2005;16:1330-8.

72. Flicker L, McCaul KA, Hankey GJ, et al. Body mass index and survival in men and women aged 70 to 75. J Am Geriatr Soc 2010;58:234-41.

73. Sonntag D, Ali S, Lehnert T, et al. Estimating the lifetime cost of childhood obesity in Germany: results of a Markov model. Pediatr Obes 2015;10:416-22.

74. Sonntag D, Ali S, De Bock F. Lifetime indirect cost of childhood overweight and obesity: a decision analytic model. Obesity 2016;24:200-6. 